\title{
PRESO PELA RATOEIRA: SOBRE A SEDUÇÃO NOS ENTREMEZES PORTUGUESES DO SÉCULO XVIII
}

\section{'PRESO PELA RATOEIRA': ABOUT THE SEDUCTION IN PORTUGUESE 'ENTREMEZES' OF THE XVIII CENTURY}

Gabriel Elysio Maia Braga ${ }^{1}$

Resumo: O presente artigo pretende analisar as representações de sedução amorosa nos Entremezes lusitanos do século XVIII. Entremezes são pequenas peças de teatro as quais eram apresentadas, em Portugal e na Espanha, em intervalos de óperas ou de uma peça mais longa, tratando de temas cotidianos, satirizando-os muitas vezes. Procura-se aqui, averiguar as relações amorosas devido às mudanças na concepção de casamento na modernidade, que segundo o historiador Alan Macfarlane (1990), começava a passar de algo arranjado pelos pais, para a escolha dos noivos, daí a importância de uma etapa que precedia o casamento, a conquista do ser amado. Esta pressupunha um processo de sedução. Tomando como referência a discussão do filósofo francês Jean Baudrillard (1990) sobre o assunto pretendemos analisar os diferentes modos de galanteio representados nas peças.

Palavras Chave: Entremezes; Sedução; Relações amorosas; Portugal no século XVIII.

Abstract: The present article pretends to analyze the representations of loving seduction in the Lusitanian 'Entremezes' of the XVIII century. 'Entremezes' are short theater plays that were presented, in Portugal and Spain, during the interval of operas or a longest play, treating of quoti-

\footnotetext{
${ }^{1}$ Estudante do curso de graduação em História - Licenciatura e Bacharelado, na Universidade Federal do Paraná (UFPR). Atualmente é bolsista do PET SESu/MEC, no qual desenvolve atividades de ensino extensão e pesquisa. Desenvolve pesquisa sobre história moderna, com enfoque nos relatos de casos de vampiros do século XVIII. Contato: gab.braga94@gmail.com.
} 
dian themes and satirizing them lots of times. It is intended here analyze the loving relationships due to changes on the concept of marriage in the Early Modern Period, that were pointed by the historian Alan Macfarlane (1990), from a thing arranged by the parents to a grooms' choice, so a new stage witch precedes marriage were developed, the conquest of the loved being. This conquest presupposed a seduction process. Taking as a reference Jean Baudrillard's discussion about this matter, we pretend to analyze the different ways of seduction that are represented in the plays.

Key Words: 'Entremezes'; Seduction; Romantic relationships; XVIII century Portugal.

O século XVIII, conhecido pela alcunha de "Século das Luzes" devido às grandes transformações nos âmbitos intelectual, social e político - como por exemplo a Revolução Francesa -, foi também um período de grandes mudanças no que concerne à vida cotidiana e às relações políticas e sociais. Grandes alterações ocorreram no âmbito familiar, como por exemplo, as apontadas por Richard Sennett e Alan Macfarlane. Sennett (1988) fala de uma maior intimidade nas relações domésticas, especialmente entre a população mais pobre, afirmando que entre a nobreza o amor familiar, pelo menos até o século XVIII, era visto como um sentimento das classes mais baixas. Macfarlane (1990) trata em seu livro das modificações na instituição do casamento, sobre as quais discorreremos neste artigo.

Outra mudança, abordada pela historiadora Joan DeJean (2005), que merece ser destacada é o desenvolvimento do termo "público" entre os séculos XVII e XVIII. A autora mostra como esta palavra vai ganhando conotação de audiência, auxiliando assim na formação da cha- 
mada esfera pública, a qual é tratada por parte da historiografia do século das luzes como um produto do Iluminismo. No entanto, a historiadora defende o surgimento de uma opinião pública já no século XVII, devido aos debates literários tanto em salões como por meio de cartas enviadas aos jornais da época. DeJean (2005) analisa a recepção de romances pelos próprios leitores, demonstrando a importância desse gênero para o desenvolvimento da opinião pública, gerando até mesmo uma querela na Academia de Letras da França, entre os chamados antigos e os modernos, quando se discutiu o impacto da popularização da opinião e da crítica, levando em consideração seu impacto no trabalho dos eruditos. ${ }^{2}$

Outro autor que também avalia a popularização da literatura neste contexto, é Roger Chartier (2012), o qual partindo do princípio de que primeiramente as pessoas aprenderiam a ler para somente após isso aprender a escrever, fez uma relação entre o número de assinaturas e o número de pessoas alfabetizadas, concluindo que na Europa entre os séculos XVI e XVIII ocorreu um aumento significativo no número de indivíduos que sabiam ler, podendo assim ter contribuído para a popularização da literatura tratada por DeJean (2005).

\footnotetext{
${ }^{2}$ Os primeiros eram contra a popularização da leitura por pensarem que com isso poderia haver uma depreciação da cultura escrita, desejavam, portanto, manter o público afastado de suas discussões. Em oposição a eles, os chamados modernos julgavam importante considerar a recepção do público e por isso eram a favor da divulgação e popularização das obras literárias. Neste contexto inclui-se também a popularização do romance. Os chamados antigos defendiam a estética da poesia, enquanto os defensores da difusão da literatura viam os romances com bons olhos, assim como as críticas que a população fazia a estes nos jornais, gerando debates públicos.
} 
Pensemos este mesmo contexto de popularização da leitura em Portugal. Um gênero teatral e também literário que obteve grande aceitação foi o Entremez, o qual, segundo Elizabeth Fonseca (2011), se propôs a satirizar situações cotidianas, criticando de maneira cômica costumes da sociedade, principalmente da aristocracia. Pode-se deduzir, segundo a autora, que o Entremez atingiu bastante popularidade - tendo como público principal, muito provavelmente, a burguesia, visto as críticas à nobreza e o poder aquisitivo para adquirir os impressos - devido ao grande número de peças que existem ainda hoje e estão disponíveis para consulta e pesquisa. Quanto à estrutura, são peças curtas, possuindo entre 15 e 24 páginas, com poucos personagens, mas que geralmente são estereotipados como: a Velha, o Peralta, o Pai.... Quanto ao cenário percebe-se uma predominância do ambiente doméstico. Importante lembrar que as peças eram escritas não necessariamente para serem encenadas, podendo ser vendidas também como literatura de cordel ${ }^{3}$.

O filósofo francês Jean Baudrillard, em seu livro, Seduction (1990), afirma que no século XVIII muito se falou sobre sedução, a qual era, segundo o autor, uma preocupação central das esferas aristocráticas, ao lado da Honra e da Coragem ${ }^{4}$, e também uma preocupação da burguesia, visto que sua ascensão possibilitou uma aproximação aos costumes da corte.

Para Baudrillard (1990) a sedução não é algo natural, mas sim um artifício utilizado com o intuito de fascinar, conquistar e encantar o ou-

\footnotetext{
${ }^{3}$ FONSECA, 2011, p. 14.

${ }^{4}$ BAUDRILLARD, 1990, p.1.
} 
tro. O universo da conquista amorosa, para ele, deve ser interpretado nos termos de jogos, desafios, duelos e estratégias de aparência ${ }^{5}$. Um objeto sedutor não reivindica uma verdade própria, apenas seduz ${ }^{6}$. Esta forma de análise, a partir de uma visão de artifício, jogo e estratégia de aparências, pode ser utilizada para analisar as relações amorosas presentes nos Entremezes cujo objetivo é a conquista do ser amado.

Quando se fala em sedução no século XVIII, a personagem Don Juan $^{7}$ e o escritor Marquês de $\operatorname{Sade}^{8}$ são lembrados. Estabelecendo as diferenças pode-se comparar os estratagemas presente nos Entremezes com a dos sadeanos e donjuanescos, que não valorizam o sentimento amoroso nos seus jogos de ludibrio predominantemente sexuais. Em seu livro La Philosophie Dans le Budoir - publicado clandestinamente em 1795 - o Marques de Sade praticamente concede aos leitores um tratado sobre a filosofia libertina, a qual não pode ser confundida com o galanteio apresentado pelos Entremezes. Os personagens de La Philosophie... não possuem apreço pelo amor, e sua diversão consiste em seduzir e "perverter" jovens como fica explicitado no trecho:

LE CHEVALIER: [...] quelles délices pour toi de la corrompre, d'étouffer dans ce jeune cœur toutes les semences de vertu et de

${ }^{5}$ Conceito chave na obra de Baudrillard. Pode-se classificar esta estratégia como um fingimento, uma encenação. Nos Entremezes é recorrente a utilização do que podemos classificar de estratégias de aparência.

${ }^{6}$ BAUDRILLARD, 1990, p. 7.

${ }^{7}$ Famoso personagem da literatura espanhola conhecido por ser um grande sedutor.

${ }^{8}$ Nascido em 2 de junho de 1740, Donatien Alphonse de Sade viveu uma vida repleta de polêmicas - em sua maioria sexuais - e prisões. Autor de Justine (1791) e Filosofia na Alcova (1795), é a representação máxima dos libertinos. 
religion qu'y placèrent ses institutrices! En vérité, cela est trop roué pour moi.

MME DE SAINT-ANGE: Il est bien sûr que je n'épargnerai rien pour la pervertir, pour dégrader, pour culbuter dans elle tous les faux principes de morale dont on aurait pu déjà l'étourdir; je veux, en deux leçons, la rendre aussi scélérate que moi... aussi impie... aussi débauchée. Préviens Dolmancé, mets-le au fait dès qu'il arrivera, pour que le venin de ses immoralités, circulant dans ce jeune cœur avec celui que j'y lancerai, parvienne à déraciner dans peu d'instants toutes les semences de vertu qui pourraient y germer sans nous ${ }^{9}$.

Nesta história narrada por Sade, no primeiro diálogo os irmãos le Chevalier e Mme de Saint-Ange conversam sobre uma recente conquista, a jovem Eugénie, que recebeu de seus pais uma virtuosa educação fundada na moral e nos princípios cristãos. O objetivo de Saint-Ange é destruir as raízes desse ensino no coração de Eugénie, tornando-a uma “adepta à fillosofia libertina”. Nos Entremezes poucas personagens se utilizam da sedução como um mero jogo ou passatempo e se há objetivo sexual, este não é explicitado. Nas peças aqui analisadas, os persona-

\footnotetext{
9“'O CAVALEIRO: [...] Que delícia, para você, corrompê-la, abafar em seu jovem coração todas as sementes de virtude e de religião que foram nela colocadas por suas mestras. Na verdade, isto é muito ardiloso para mim.

MADAME DE SAINT-ANGE: É certo que nada pouparei para pervertê-la, para degradá-la, para fazer cair os princípios morais que já começam a atordoála; pretendo, em suas lições, fazê-la tornar-se tão trapaceira quanto eu... tão ímpia... tão pervertida. Avise Dolmancé, avise-o no momento se sua chegada, para que o veneno de suas imoralidades circulem no jovem coração juntamente ao que lançarei, desenraizando, assim, em pouco tempo, todas as sementes de virtude de lá germinariam, não fosse nossa interferência." [Tradução Livre] Cf. SADE, Marquis de. La Philosophie Dans Le Boudoirou Les Instituteurs immoraux. La Bibliothèque électronique du Québec. Collection Libertinage. Volume 6: Version 1.0. Disponível em: <http://beq.ebooksgratuits.com/libertinage/Sade_La_philosophie_dans_le_boud oir.pdf $>$ acesso em: 13/05/2014.
} 
gens não abrem mão de seu sentimento amoroso, e o objetivo final da sedução é o casamento e não a relação sexual.

Um tema frequentemente abordado nos Entremezes foi o das relações amorosas. O matrimônio recorrentemente aparece para que pudesse ser contestada a prática das bodas arranjadas ${ }^{10}$, logo, são frequentes as uniões que ocorrem por vontade dos noivos, o "casamento por amor", que se torna mais comum a partir da primeira metade do século $\mathrm{XVIII}^{11}$.

Nas bodas arranjadas pelos pais o futuro casal muitas vezes não se conhecia previamente, diferentemente desta nesta nova prática de união, em que o amor tem um papel importante. Sendo assim é necessário que os noivos se conheçam, desenvolvam uma relação e desejem casar, embora isto não seja uma regra. Como será apresentado a seguir, o matrimônio também poderia ocorrer por puro interesse econômico. Importante ressaltar que mesmo com as mudanças percebidas quanto ao consentimento paterno os próprios noivos escolhiam seus futuros cônjuges de acordo com certos parâmetros. Macfarlane (1990) explicita que eram relevantes fatores como idade e paixão, mas também aspectos econômicos, como as posses e o dote ${ }^{12}$. Um exemplo que pode ser apontado é a criada da peça Os Desprezos de Hum Filho Peralta a seu Pai (1792), a qual afirma que facilmente trocaria o peralta que a havia jura-

${ }^{10}$ FONSECA, 2011, p. 25.

${ }^{11}$ DANTAS, s/d, p.214.

${ }^{12}$ MACFARLANE, 1990, p. 154. 
do amor por um homem que fosse mais rico ${ }^{13}$. Importante ressaltar que este fator econômico não era visto como algo ruim, contanto que o casamento ocorresse pela vontade dos noivos.

Na peça O Cazamento De Huma Velha Com Hum Peralta (s/d), observa-se que o rapaz assume que casou pelo dote. Numa fala do criado pode-se concluir que o que indigna as outras personagens não é o motivo da união, mas sim o fato de o Peralta não tratar bem sua companheira. Macfarlane (1990) explica que há uma obrigação social de que o homem ame sua esposa ${ }^{14}$, e pode-se observar esta demanda por meio das falas dos criados Salafrário e Ladina. Diz o primeiro:

Vossa mercê certamente naõ tem a consciencia, a pobre Senhora
baba-se por vossa mercê, cada vez lhe quer mais, e ainda em si-
ma a despreza, e lhe dá tão má vida, se eu tivesse a fortuna de en-
contrar huma velha rica, e quizesse cazar comigo, trazia-a nas
meninas dos olhos, fazia-lhe quantas vontades Ella quizesse; pois
tudo merecia o belle dinheiro, enteriormente me aborreceria; mas
nunca lhe havia de dar a conhecer a má vontade que lhe concer-
vava. ${ }^{15}$ Pode-se deduzir a partir desta fala que mesmo não sendo o casamento realizado por motivos de amor, o importante - para a esfera social - é que as aparências sejam mantidas.

\footnotetext{
${ }^{13}$ Novo Entremez Intitulado Os Desprezos de Hum Filho Peralta a seu Pai; ou Sophismas, com que Enganou a Criada. Lisboa, Officina de Francisco Borges de Souza, 1792, pp; 6-7.

${ }^{14}$ MACFARLANE, 1990, p. 197.

${ }^{15}$ Novo, e devertido Entremez Intitulado O Cazamento de Huma Velha Com Hum Peralta e a Ma'Vida Que Elle Lhe Deu. Lisbos, Officina de Domingos Gonsalves, s/d, pp. 2-3. Optou-se por manter a grafia como no original.
} 
Selecionamos, para esta análise sobre a sedução, 18 Entremezes em que o casamento ocorre pela vontade dos noivos. Macfarlane (1990) aponta que para a Inglaterra do século XVIII o consentimento dos pais já não era algo necessário para que o matrimônio ocorresse. Nas peças selecionadas é possível perceber um conflito entre o forte controle paterno e a pungente opinião e anseio pela tomada de decisão dos jovens. O foco aqui, contudo, é a relação amorosa antes do casamento. Tal relação implica em conquistar o ser amado, seduzi-lo. Especialmente com a nova concepção de casamento por amor, os noivos terão que se esforçar cada vez mais para poder seduzir e conquistar o amor do ser desejado.

Em todas as peças analisadas há a presença de táticas de conquista nas falas e atitudes das personagens, em sua maioria com a finalidade de que ocorra o casamento, entretanto, em alguns casos, a conquista amorosa aparece como um mero passatempo, uma diversão, geralmente de homens. Entretanto, na peça intitulada A Ratoeira Em Que Amor Pilha Os Pobres Namorados (s/d), as mulheres são as donas da sedução ${ }^{16}$. Nesta história três mulheres, duas jovens, Clarice e Arminda, e uma Velha ${ }^{17}$, Guimar, discutem acerca de como não é difícil seduzir homens e controlá-los, embora eles pensem que são mais sagazes. Este pensamento masculino, de pensar que estão no comando, faz com que as três mulheres riam. Clarice constata: "Que loucos saõ os homens, em

\footnotetext{
${ }^{16}$ Nesta peça, duas jovens falam que vão conquistar seus amantes, e Guimar as ajuda a bolar estratégias para que obtenham sucesso, em uma das falas ela afirma: "[eles] hão de cahir na ratoeira". Por isso a escolha para o título deste artigo.

${ }^{17}$ A Velha é uma personagem recorrente deste tipo de teatro.
} 
prezumirem de sagazes? em nós querendo, cantamos o vencimento"18. Arminda explica melhor: "a hum leve volver dos nossos olhos, cahe por terra todo o Poderozo edifício da sua prezunção"19. Edifício este que pode ser compreendido como a construção e o fingimento de uma personagem pensada estrategicamente com a finalidade de conquistar. Este fingimento é como um jogo visto em termos de desafio no qual a estratégia de aparências é um artifício, uma arma.

A estratégia de aparências é um dos pontos da tese de Baudrillard que pode ser utilizado para analisar a sedução nos Entremezes, visto a grande ocorrência de papéis encenados pelas personagens. Pode-se citar três tipos principais de imagens construídas pelas personagens: o amante sofredor, o herói, e o amante irado ou enciumado, ou como aparece nos Entremezes, fazer arrufos ${ }^{20}$.

\section{O Amante Sofredor}

Elementos constantes neste discurso, na maioria das vezes masculino, são a Saudade e a Fidelidade, principalmente o primeiro, utilizado para relatar à pessoa amada todo o sofrimento passado durante os momentos em que esta não estava presente, podendo-se concluir que nas peças é um artifício dizer que existe uma angústia quando da ausência

\footnotetext{
${ }^{18}$ Novo e Graciozo Entremez Intitulado A Ratoeira Em Que Amor Pilha Os Pobres Namorados. Lisboa, Officina de Antonio Gomes, s/d, p. 1.

${ }^{19}$ Ibidem, p. 2.

${ }^{20}$ Fazer arrufos é aparentar uma pequena ira ou raiva, com o intuito de observar como se portará o amante diante desta situação.
} 
do outro. "Quem tem amores naõ dorme" ${ }^{21}$ diria Pelaio, o criado do Entremez Amor Artífice (1782), "Nem mais póde socegar" declamam pela janela: "Querido bem deste meu peito, / Auzente da tua vista / Naõ faz mais que suspirar.". ${ }^{23} \mathrm{Na}$ peça $O$ Libertino Castigado (1789), o criado Galope ajuda seu amo Faceto na construção desta imagem. Ele conta que o amo sofria por sua amada e só possuía pensamentos para ela, tanto que um dia, por não conseguir pensar em outra coisa, saiu com três chapéus, um na mão, outro na cabeça e o terceiro em baixo do braço ${ }^{24}$.

Este sofrimento também pode ser observado nos amantes Arminda e Bazófio, da peça A Primeira Parte Do Velho Impertinente (s/d). Ambos se utilizam dessa aparência para seduzir. A moça diz que não pode sossegar um só instante longe do seu namorado e o galanteador proclama: "Em quanto me não vejo nos seus braços. Sinto, esta alma desfeita em mil pedaços" 25 . Amandio, da peça A Ratoeira, afirma: "O meu coraçaõ naõ pode hum só momento deixar o amável objecto, porque anciozamente suspira". ${ }^{26}$ Frazino utiliza da mesma estratégia, dizendo que os instantes parecem séculos quando está longe de sua ben-

${ }^{21}$ Novo Entremez, O Amor Artífice. Lisboa, Officina de Antonio Rodrigo Galhardo, 1782, p. 2

${ }^{22}$ Idem.

${ }^{23}$ Idem.

${ }^{24}$ Pequena Peça Intitulada: O Libertino Castigado e a Prizão No Jogo de Bilhar. Lisboa, Officina de Simão Thaddeo Ferreira, 1789, p. 7.

${ }^{25}$ Ibidem, p. 8.

${ }^{26}$ Novo e Graciozo Entremez Intitulado A Ratoeira Em Que Amor Pilha Os Pobres Namorados. Op. cit., p. 5. 
quista. Amandio e Frazino utilizam essa tática mais com o intuito de se divertirem, como veremos mais à frente.

Em certos casos, para expressar a inquietação, o amante diz sentir no coração "tantos, tantos formigueiros" ${ }^{27}$. Em Cazamento Gostozo (1777), a criada Alegria declara sentir um formigueiro dentro dela ${ }^{28} \mathrm{em}$ um momento em que está sendo seduzida por Marruz ${ }^{29}$. Na peça Amantes Arrufados (s/d), após o criado Marotinho relatar que sua estimada dama e a de seu senhor estão "danadas" com eles, o amo Felisberto propõe fazer ciúmes, Marotinho diz que não adiantaria, mas o amo diz: "Como te enganas, sempre o amor primeiro/ Deixa no coração um formigueiro" ${ }^{30}$. Interessante observar que na peça Os Velhos Amantes (1784), se apresenta um remédio para curar o formigueiro: o casamento ${ }^{31}$.

O encontro com a pessoa amada é relatado como um alívio ao coração, como diz o já citado Galope - do Entremez O Libertino Castigado (1789) -, quando acompanhado de seu amo encontra as respectivas amantes: "vimos aqui para alliviar as saudades, que nos esfrangalhão o

${ }^{27}$ Os Velhos Amantes: Pequena Peça, ou Novo Entremez. Lisboa, Officina de Simão Thaddeo Ferreira, 1784, p. 11.

${ }^{28}$ Alegria afirma isso em pensamento, pois está fazendo arrufos, sendo assim, não pode demonstrar que se sente atraído por Marruz. Tratarei desse caso adiante.

${ }^{29}$ Novo Entremez Intitulado, O Cazamento Gostozo. Lisboa, Officina de Caetano Ferreira da Costa, 1777, p. 8.

${ }^{30}$ Novo Entremez Intitulado Os Amantes Arrufados. Lisboa, Officina de Antonio Gomes, s/d, p. 2.

${ }^{31}$ Os Velhos Amantes: Pequena Peça, ou Novo Entremez. Op. cit., p. 11. 
coração" 32 . Ou o "padeço de tirannas saudades" amante de Disfarce, criado que na peça Os Disgostos Que Teve Huma Sécia De Lisboa (1789), ao ir entregar uma carta à namorada de seu amo, na casa dela, tropeça em um cachorro e pelos latidos é denunciado, acordando o pai da moça que confisca a carta. Devido ao ocorrido, Disfarce, ao longo da peça várias vezes cita o ato, para mostrar como ele é um amante esforçado, contudo há na fala do criado um tom exageradamente heroico.

\section{O Amante Herói}

Outro estratagema que mais parece uma autoafirmação masculina, como protetor, ou como um valente que enfrenta o perigo, é a estratégia que será aqui chamada de $O$ Amante Herói. O já citado Disfarce da peça Os Disgostos Que Teve Huma Sécia De Lisboa (1789) - utilizase do ocorrido para enaltecer sua imagem, para ressaltar que seria capaz de um sacrifício em nome do amor. Diz ele: "Olha rapariga, por amor de ti me expuz a ser escovado pelo amigo morraõ ${ }^{\prime 34}$ e completa que o cão só não avançou porque sabia que iria perder a luta. Em outra fala, quando está se retirando e percebe que terá de passar pelo cachorro mais uma vez, relata isso para sua benquista como se fosse enfrentar uma verdadeira aventura. Tal valentia é utilizada como recurso cômico e sua ama-

\footnotetext{
${ }^{32}$ Pequena Peça Intitulada: O Libertino Castigado e a Prizão No Jogo de Bilhar. Op. Cit. p. 7.

${ }^{33}$ Novo e Devertido Entremez Intitulado Os Disgostos Que Teve Huma Sécia de Lisboa, Por Amor do Seu Amante. Lisboa, Officina de Francisco Borges de Souza, 1789 , p. 7.

${ }^{34}$ Ibidem, p. 8.
} 
da, zombando de sua "valentia", questiona: "naõ me pareces homem pelo muito medo que mostras; quem teme um cão? Só tu.".35

Não só a coragem como também a aparência do herói libertador, como na peça A Peta De Nova Invenção (1790), na qual Florindo, em uma carta a Lucrecia, sua amante, escreve: "Unica prenda da minha alma, hum momento não passa, em que eu, e meu esperto criado, não estejemos a discorrer no modo de a resgatar desse pessimo captiveiro" ${ }^{\text {"36. }}$.

\section{Fazer Arrufos ou Namorar por Nova Ideia}

Fator importante para compreender a sedução, principalmente feminina, é o fazer arrufos, também chamado de namorar por nova ideia $^{37}$. Em Cazamento Por Nova Ideia (1792), Angélica afirma que o intuito de fingir arrufos é ver os homens "morrerem por nós",38, o que também pode ser observado no Entremez A Ratoeira (s/d), no qual as jovens afirmam que com apenas "sutis invetivas" ${ }^{39}$ os homens], cédem, e ficão como mansos cordeirinhos.". 40

Essa nova estratégia de aparência é ironizada pelo criado Merlim, do Entremez Amor Sem Pés Nem Cabeça:

\footnotetext{
${ }^{35}$ Idem.

${ }^{36}$ Novo e Gracioso Entremez Intitulado A Peta de Nova Invenção, Ou O Ciozo Enganado. Lisboa, Officina de Francisco Borges de Souza, 1790, p. 6.

${ }^{37}$ Fazer arrufos ou namorar por nova ideia é uma tática de sedução utilizada nos entremezes que consiste em fingir ira ou ciúmes.

${ }^{38}$ Novo e Devertido Entremez Intitulado Cazamento Por Nova Ideia. Lisboa, Officina de Francisco Borges de Souza, 1792, p. 5.

${ }^{39}$ Segundo Bluteau (1728), inventiva é uma repreensão por palavras ásperas.

${ }^{40}$ Novo e Graciozo Entremez Intitulado A Ratoeira Em Que Amor Pilha Os Pobres Namorados. Op. Cit. p. 1.
} 
Senhor meu Amo, juro-lhe que este seu modo de viver fará rir a todos: V.m. com o seu maldito amor he peior que os doidos, eu dezejava que todo o mundo vira o seu modo de tratar para com a sua amada? Agora the faz agrados, logo carranca, e taõ feia, que para desmamar huma criança, naõ te precizava mais: se em hum instante estaõ de sera, dali a nada já os vejo com sete pedras na maõ; emfim He o seu amor, amor sem pés nem cabeça; nunca se sabe quando estaõ bem, ou mal $[\ldots]^{41}$

Armelindo responde a seu indignado criado, procurando justificar:

As tuas parollas me divertem quanto te naõ sei encarecer; queres por ventura, que naõ hajaõ mais do que meiguices, agradinhos, e nunca o semblante irado! como és simples, naõ sabes, que em qualquer mulher tomando posse, e conhecimento do coraçaõ de hum homem, o despreza, e o trata como lhe parece! [...]; bem mostras que do mundo naõ tens o menor conhecimento, e muito ${ }_{42}$ menos dos venozos extratagemas, e sutís idéias do sexo variavel.

Pode-se perceber neste diálogo, principalmente quando o amo diz que o criado não conhece o mundo, que a prática de encarnar uma personagem - fingir uma aparência - não era incomum. Os venenozos extratagemas, eram até mesmo esperados pelo amante, eram uma estratégia de sedução.

Na peça Amantes Desconfiados (1777), ambos os namorados desconfiam que a pessoa amada está apaixonada por outra, sendo assim os serviçais decidem aconselhar seus respectivos amos a fingir que estão arrufados. Na hora os senhores ficam receosos, mas os primeiros aconselham que permaneçam com a encenação.

\footnotetext{
${ }^{41}$ Novo e Gracioso Entremez Intitulado Amor Sem Pés Nem Cabeça. Lisboa, Officina de Francisco Borges de Souza, 1789, p. 1.

${ }^{42}$ Idem.
} 
Nos Entremezes fazer arrufos é uma tática, uma encenação, uma estratégia de aparências. Alegria, quando cortejada por Marruz, embora esteja por ele seduzida, mostra-se firme em sua tática de aparentar um arrufo, mesmo sentindo o já citado formigueiro em seu coração. Pode-se perceber ao decorrer das peças que essa artimanha geralmente é bemsucedida; a personagem Dorina do Entremez Amantes Arrufados (s/d) diz que "mais amais quando tem maior ciûme" ${ }^{43}$. Contudo, esse artifício não obtém sucesso sempre ${ }^{44}$. Ao ser colocada em dúvida a fidelidade do amante, este, muitas vezes, sente-se ofendido, arrufando-se verdadeiramente, o que obriga o outro a abrir mão de sua estratégia de aparências e confessar que tudo era apenas fingimento, como ocorre em Cazamento Por Nova Ideia: "Meu querido Rimantes, perdoa, o meu excessivo amor deu cauza a este ciúme, tudo foi fingido, eu estou certificada da tua firmeza"45 clama Angelica ao seu amado, pedindo-lhe perdão pelo ocorrido. Bacello constata: "Tenho percebido, isto he o que se chamaõ namorados por nova ideia, tudo nicas, tudo ciúmes, e no cabo nada [...]"46, ou seja, contata-se que foi considerado importante, pelo autor da peça, ressaltar o "namorar por nova ideia" nesta representação do amor dos jovens.

\footnotetext{
${ }^{43}$ Novo Entremez Intitulado Os Amantes Arrufados.Op. Cit. p. 10.

${ }^{44} \mathrm{O}$ que claramente é um recurso cômico.

${ }^{45}$ Novo e Devertido Entremez Intitulado Cazamento Por Nova Ideia. Op. Cit. p. 9.

${ }^{46}$ Idem.
} 


\section{Sedução como Passatempo ou Batalha}

Muitas personagens se referem à sedução como um divertimento, um passatempo, um jogo, outros, verdadeiramente apaixonados, chegam a comparar a conquista a uma verdadeira batalha. Sobre o primeiro caso, o Peralta Aurélio da peça A Grande Desordem De Huma Velha Com Hum Peralta (1790) afirma que "naõ há divertimento melhor do que fingir amor a huma Velha”, ${ }^{47}$ e isso é reforçado pela própria criada da Velha, Lésbia, a qual admite ser divertido ver o Peralta fingir amor à sua ama. Aurélio vai além: "[...] que he amar a huma só mulher? Carta a huma, hum verso a outra, a esta huma fineza, aquella huma lisonja; he hum passatempo o mais divertido, que se póde imaginar" ${ }^{\text {"48 }}$. Baudrillard afirma que "pode-se seduzir outro com o intuito de seduzir um terceiro, contudo, pode-se também seduzir alguém para agradar a si mesmo"49, assim como pode-se observar que muitos Peraltas utilizam as estratégias de aparência não como uma forma de conquistar a afeição do outro, mas sim como uma forma de se divertir e até mesmo de se auto afirmar como galante para seu próprio prazer. Os rapazes de A Ratoeira divertemse lendo as cartas de suas amadas e riem ao escrever versos apaixonados às damas. Para eles a sedução é uma diversão.

Não só por diversão, mas também como uma forma de enganar o pai para que o jovem galanteador possa casar com sua benquista. No

\footnotetext{
${ }^{47}$ Novo e Divertido Entremez Intitulado A Grande Desordem de Huma Velha com Hum Peralta Por Não Querer Casar Com Ella. Lisboa, Officina de Antonio Gomes, 1790, p. 1.

${ }^{48}$ Ibidem, p. 2.

${ }^{49}$ BAUDRILLARD, 1991, p. 81. [tradução livre]
} 
Entremez $O$ Velho Peralta (1776), Felisberto e Simplicio, para poderem casar com Ifigenia e Lizarda, bolam um plano ${ }^{50}$ para enganar o Velho Trifonio. Este estratagema montado pelos jovens apaixonados consiste em contratar uma cigana espanhola, Pepa, para que ela encantasse o Velho, a fim de que o casamento pudesse ser consumado. Ao vê-la, Trifonio logo se encanta pelo seu modo meigo e carinhoso, aproveitando-se da situação a espanhola afirma não poder amá-lo devido ao modo como o Velho se traja e explica que gosta de "muxaxos" que se vestem como peraltas ${ }^{51}$. Fascinado, o Velho tenta satisfazer as vontades da cigana, contudo o alcaide é avisado e Trifonio é preso por se trajar inadequadamente para a sua idade. Sendo assim, os namorados podem se casar tranquilamente.

A conquista também é vista nos Entremezes lusitanos como um duelo, uma espécie de desafio. "E o que pode ser mais sedutor do que um desafio?"52. Para enfrentar uma batalha, mais seguro é quando se tem à disposição armas e quais seriam as armas da sedução? Clarice as descreve: "mil fingimentos, lagrimas amiudadas, soluços arrancados do interior, sejaõ as armas com que vençamos a batalha",53. Arminda complementa:

\footnotetext{
${ }^{50}$ Importante constatar que nos Entremezes pode ser observada uma grande variedade de planos com o intuito de enganar o pai, contudo, como o foco neste artigo são as relações de sedução, apenas o plano apresentado neste Entremez será citado, pois foi o único caso encontrado desse tipo no qual há sedução.

${ }^{51}$ Entremez Intitulado: $O$ Velho Peralta. Lisboa, Officina de Francisco Sabino dos Santos, 1776, p. 12.

${ }^{52}$ BAUDRILLARD, 1991, p. 82. [tradução livre]

${ }^{53}$ Novo e Graciozo Entremez Intitulado A Ratoeira Em Que Amor Pilha Os Pobres Namorados. Op. Cit. p. 2.
} 
Clamar contra os tyranos; chamar-lhe mil vezes cruéis assassinos do nosso socego, roubadores do coraçaõ, e logo o flagelador do ciúme; apár destas astudadas palavras, deve fazer o seu dever; chorar-se então, suspira-se, e certamente o triunfo será nosso, seremos Espozas, e conseguiremos desagravar Amor, destas almas de bronze, que os desprezaõ ${ }^{54}$.

Interessante observar a questão do estudo, pois ela é também citada em outras peças como, por exemplo, em Correção das Vaidosas (1819). Neste Entremez as irmãs Silvia e Livia discutem acerca de como seduzir os homens. Enquanto Silvia, que procura mostrar erudição encaixando palavras em latim - não seguindo as regras formais de gramática, o que auxilia na comicidade da situação - em suas falas, diz para a irmã abandonar os adornos, pois estes, em sua concepção seriam supérfluos, e sugere o estudo, pois, para ela, é o encanto que verdadeiramente cativa os homens; Livia, a qual também para mostrar cultura termina suas falas com palavras em italiano, retruca e diz que não há coisa mais forte que os adereços, pois, segundo ela, os homens não olham para outra coisa.

Na peça O Peralta Disvelado e a Dama Desvanecida (1778), o criado Centurio afirma que as moças se divertem enganando os homens, sendo que para ludibriá-los não é preciso apenas dizer que os amam, mas também que elas ajam como os sapateiros, os quais sempre procuram convencer o cliente que o seu produto é o melhor ${ }^{55}$. Logo se percebe que a conquista é um desafio muitas vezes pessoal, de aperfeiçoa-

\footnotetext{
${ }^{54}$ Ibidem, pp. 2-3.

${ }^{55}$ Novo Entremez Intitulado: O Peralta Disvelado, e a Dama Desvanecida. Lisboa, Officina de Francisco Sabino dos Santos, 1778, pp. 2-3.
} 
mento das técnicas de cativação. Pode-se concluir que a conquista exigia certo conhecimento, um saber passado de geração a geração sobre o que fascina o outro, como encantar e como proceder durante esse processo. Para isso também era importante saber qual local era mais adequado para que ocorresse o galanteio.

\section{Os Lugares da Sedução}

Nos Entremezes, pode-se perceber que a sedução não ocorre em qualquer lugar, dois são os que mais se destacam: a Janela e o Jardim. O namoro de janela, chamado por Júlio $\operatorname{Dantas}^{56}(\mathrm{~s} / \mathrm{d})$ de galanteio de janela-abaixo, era algo comum na cidade de Lisboa e aparece em A Peta de Nova Invenção (1790). Nesta peça, a já citada Lucrecia, presa nas garras de um Velho, fala para sua criada o quão enganado está seu tutor acerca de sua janela, pois ela "mil vezes se abre, e della se comunicão os amáveis sentimentos dos nossos peitos constantes" ${ }^{\text {,57 }}$. É importante lembrar que Dantas escreve sobre a primeira metade do século XVIII e as fontes escolhidas remetem à segunda metade. Tais relatos podem nos informa que muitos aspectos da vida galanteadora/amorosa portuguesa como a paquera através da janela - ainda eram presentes mesmo após algumas décadas.

\footnotetext{
${ }^{56}$ Intelectual português do início do século XX, bastante conhecido pela escrita de peças teatrais. Foi ministro em Portugal e embaixador de seu país no Brasil durante a década de 1940. Escreveu O Amor em Portugal no século XVII em 1915.

${ }^{57}$ Novo e Gracioso Entremez Intitulado A Peta de Nova Invenção, Ou O Ciozo Enganado.Op. Cit. p. 5.
} 
A janela representava um perigo tão grande, na visão do pai ou do tutor, que no Entremez Amor Artífice (1782), peça na qual uma parte dos diálogos entre os amantes é feita através da mesma, o tutor Geronte expressa sua vontade de tampá-las para que possa ficar descansado ${ }^{58}$. O próprio Júlio Dantas, afirma que os galanteadores já saiam do ventre da mãe conhecendo todo o ritual de namoro à fenestra, o qual exigia discrição. ${ }^{59}$

Quanto ao jardim, é o local preferido, principalmente quando da utilização da aparência de arrufado. O quintal é onde o criado se esconde para observar a amada de seu amo e dizer-lhe como ela está, é também o local onde patrão e criado ficam em muitos casos escondidos a espera de suas amadas, ou apenas observando-as. Ao encontro deles, inicia-se o discurso apaixonado. Ponto também importante é a presença das cartas amorosas trocadas entre os amantes.

\section{Considerações Finais}

Analisando as peças, pode-se ter uma breve ideia acerca de como se davam as relações de sedução na Portugal do século XVIII. Através dos Entremezes observamos quais aspectos destas relações eram destacados para estar no teatro. Pode-se deduzir, a partir da grande frequência de representações de estratégias de aparências nas peças, que esta era uma prática um tanto comum entre os jovens lusitanos das classes altas, e motivo de sátira por outros setores da sociedade. Importante ressaltar o

\footnotetext{
${ }^{58}$ Novo Entremez, O Amor Artífice. Op. Cit. pp. 4-5.

${ }^{59}$ DANTAS, s/d, p. 49.
} 
papel da estratégia de aparências como um enigma, elemento tão ressaltado pelo pensador dinamarquês Kierkegaard, em seu Diário de um Sedutor $^{60}$. O enigma provoca um desafio, o qual envolve os dois amantes (ou em certos casos, mais do que dois). Um jogo, cujo objetivo é a conquista, se inicia, exigindo dos participantes disposição e vontade. E pelo apresentado nas peças, pode-se questionar se os próprios portugueses não viam a sedução como um jogo. Este, porém, é bastante diferente do jogo do Marquês de Sade.

A representação da conquista nos Entremezes, que em muito é consequência do casamento por vontade dos noivos, está situada dentro do conflito "Tradição versus Novos Costumes". Essas novas condutas, muitas vezes são criticados comicamente, como a constante confusão causada por fingir arrufos. $\mathrm{O}$ amante herói que na realidade não é tão corajoso, o sofredor que treina o que falar para a amada, a carta mal escondida e os inúmeros planos bolados pensando no casamento, podem ser tidos como elementos burlescos de sátira às novas formas de amor. Contudo, o recorrente final feliz e a usual crítica ao matrimônio arranjado podem levar a crer que embora exista um discurso conservador, esse novo modo de união matrimonial é sim levado em consideração podendo supor que a nova forma de união e, por consequência, o processo de conquista fossem considerados fundamentais pelos lusitanos para sua própria a compreensão. Talvez essa importância dada à sedução expli-

\footnotetext{
${ }^{60}$ Em um trecho de sua obra, Johannes, o sedutor, intrigado com o enigma que Cordélia, a quem está dirigida a sedução, o proporciona. O diarista suplica que não está implorando que sua amada apareça, mas sim desafiando-a para um combate.
} 
que a fama de homens como Giacomo Casanova, especialistas nesta arte. Essa preocupação leva a crer que há uma vontade em desvendar os segredos da conquista. Baudrillard (1990) concorda com Kierkegaard quando este afirma que a sedução possui um cenário espiritual, que no século XVIII é como se fosse uma união entre inteligência, charme e refinamento.

Por último, é importante citar uma reflexão presente em Baudrillard (1990). Seja o peralta que ludibria por diversão ou o apaixonado por puro amor, o melhor jeito de fascinar é ser seduzido, ou pelo menos fingi-lo. Faz parte do encantamento do outro deixá-lo provocado a aceitar o desafio proposto pela sedução. Esta provocação, nos Entremezes, dava-se através das estratégias de aparência que elencamos neste artigo.

\section{Fontes}

Entremez Intitulado: $O$ Velho Peralta. Lisboa, Officina de Francisco Sabino dos Santos, 1776.

Entremez Novo, Intitulado: A Primeira Parte do Velho Impertinente, E Allucinado, Entre Amor Ardiloso e Disfarçado. Lisboa, Officina de Simão Thaddeo Ferreira, s/d.

Novo Entremez Intitulado A Correção das Vaidosas. Lisboa, Na Impressão de Alcobia, 1819.

Novo e Divertido Entremez Intitulado A Grande Desordem de Huma Velha com Hum Peralta Por Não Querer Casar Com Ella. Lisboa, Officina de Antonio Gomes, 1790. 
Novo e Devertido Entremez Intitulado Cazamento Por Nova Ideia. Lisboa, Officina de Francisco Borges de Souza, 1792.

Novo, e Devertido Entremez Intitulado O Cazamento de Huma Velha Com Hum Peralta e a Ma' Vida Que Elle Lhe Deu. Lisbos, Officina de Domingos Gonsalves, s/d.

Novo Entremez, O Amor Artífice. Lisboa, Officina de Antonio Rodrigo Galhardo, 1782.

Novo Entremez Intitulado, O Cazamento Gostozo. Lisboa, Officina de Caetano Ferreira da Costa, 1777.

Novo e Devertido Entremez Intitulado Os Disgostos Que Teve Huma Sécia de Lisboa, Por Amor do Seu Amante. Lisboa, Officina de Francisco Borges de Souza, 1789.

Novo Entremez Intitulado: O Peralta Disvelado, e a Dama Desvanecida. Lisboa, Officina de Francisco Sabino dos Santos, 1778.

Novo Entremez Intitulado Os Amantes Arrufados. Lisboa, Officina de Antonio Gomes, s/d.

Novo Entremez Intitulado: Os Amantes Desconfiados. Lisboa, Officina de Francisco Sabino dos Santos, 1777.

Novo Entremez Intitulado Os Desprezos de Hum Filho Peralta a seu Pai; ou Sophismas, com que Enganou a Criada. Lisboa, Officina de Francisco Borges de Souza, 1792.

Novo e Gracioso Entremez Intitulado A Peta de Nova Invenção, Ou O Ciozo Enganado. Lisboa, Officina de Francisco Borges de Souza, 1790.

Novo e Graciozo Entremez Intitulado A Ratoeira Em Que Amor Pilha Os Pobres Namorados. Lisboa, Officina de Antonio Gomes, s/d. 
Novo e Gracioso Entremez Intitulado Amor Sem Pés Nem Cabeça. Lisboa, Officina de Francisco Borges de Souza, 1789.

Os Velhos Amantes: Pequena Peça, ou Novo Entremez. Lisboa, Officina de Simão Thaddeo Ferreira, 1784.

Pequena Peça Intitulada: O Libertino Castigado e a Prizão No Jogo de Bilhar. Lisboa, Officina de Simão Thaddeo Ferreira, 1789.

DANTAS, Júlio. O Amor em Portugal no Século XVIII. $3^{\mathrm{a}}$ ed. Lisboa: Sociedade Editora Arthur Brandão \& Cia, s/d.

\section{Referências}

BAUDRILLARD, J. Seduction. Trad. Brian Singer. Montréal: New World Perspectives, 1990.

BLUTEAU, Raphael. Vocabulário Português e Latino. 1728.

CHARTIER, R. As práticas da escrita. In: ARIÈS \& CHARTIER (orgs). História da vida privada 3: Da Renascença ao Século das Luzes. $2^{\mathrm{a}}$ reimpressão. Trad: Hildegard Feist. São Paulo: Cia das Letras, 2012. pp.113-162.

DEJEAN, Joan. A invenção de um público para a literatura. In: Antigos Contra Modernos: as guerras culturais e a construção de um fin de siècle. Trad. Zaida Maldonado. Rio de Janeiro: Civilização Brasileira: 2005.

FONSECA, E. P. A. O casamento segundo o teatro de cordel em Portugal (1783-1794).60 f. Monografia (Graduação em História) - Setor de Ciências Humanas, Universidade Federal do Paraná, Curitiba, 2011.

MCFARLANE, A. História do casamento e do amor. Trad. Paulo Neves. São Paulo: Companhia das Letras, 1990. 
Cadernos de Clio, Curitiba, v. 6, nº 2, 2015

MORAES, Eliana R. Marquês de Sade: um libertino no salão dos filósofos. São Paulo: EDUC, 1992.

SENNETT, R. O Declínio do Homem Público: as tiranias da intimidade. São Paulo: Companhia das Letras, 1988.

Recebido em: 31/05/2015 Aceito em: 13/11/2015 